\title{
Physics-Based Scenario of Earthquake Cycles on the Ventura Thrust System, California: The Effect of Variable Friction and Fault Geometry
}

\author{
Su Qing Miranda Ong, ${ }^{1}$ (D) Sylvain Barbot, ${ }^{1,2,3}$ and Judith Hubbard ${ }^{1,2}$
}

\begin{abstract}
The Ventura Thrust system in California is capable of producing large magnitude earthquakes. Geological studies suggest that the fault geometry is complex, composed of multiple segments at different dips: thrust ramps dipping $30^{\circ}-50^{\circ}$ linked with bed-parallel décollements dipping $<10^{\circ}$. These latter types of gently dipping faults form due to preexisting weaknesses in the crust, and therefore have different frictional parameters from thrust ramps; the faults also experience different stresses because of how stresses are resolved onto the fault planes. Here, we use a twodimensional fault model to assess how geometry and frictional properties of the ramp/décollement system should affect the seismic cycle. We test velocity-strengthening, velocity-weakening, and conditionally stable décollements, and in addition explore how the dip angle of the décollement changes the earthquake behavior. A velocity-strengthening décollement cannot replicate the throughgoing earthquake ruptures that have been inferred for the Ventura fault system. We therefore suggest that this and other décollements may be better represented using a velocity-weakening or conditionally stable response. Our results show that minor variations in fault geometry produce slip amounts and recurrence intervals that differ only by $10-20 \%$, but do not fundamentally alter the types of earthquakes and interseismic slip. We conclude that geological constraints on fault geometry are typically sufficient to produce modeled earthquake sequences that are statistically consistent with paleoseismic records. However, both frictional parameters along the fault and effective normal stress influence earthquake rupture patterns significantly. More research is needed to adequately constrain these quantities in order for earthquake rupture models to work as effective predictors of fault behavior.
\end{abstract}

Electronic supplementary material The online version of this article (https://doi.org/10.1007/s00024-019-02111-9) contains supplementary material, which is available to authorized users.

1 Asian School of Environment, Singapore, Singapore. E-mail: mirandaosq@gmail.com

2 Earth Observatory of Singapore, Singapore, Singapore.

3 Present Address: Department of Earth Sciences, University of Southern California, Los Angeles, USA.

\section{Introduction}

Continental thrust fault systems are capable of producing large magnitude earthquakes, often near large population centers (e.g., $2008 \quad \mathrm{M}_{\mathrm{w}}=7.9$ Wenchuan earthquake, China; $2015 \mathrm{M}_{\mathrm{w}}=7.8$ Gorkha earthquake, Nepal). In California, although the majority of the plate boundary is defined by the rightlateral strike-slip San Andreas system, there is also significant hazard from thrust systems due to the complexity of the fault network (Davis and Namson 1994; Hauksson et al. 1995; Rubin et al. 1998; Shaw and Shearer 1999; Dolan and Rockwell 2001; Anderson et al. 2003; Lavé and Burbank 2004; Daout et al. 2016; McPhillips and Scharer 2018; Rollins et al. 2018). The Western Transverse Ranges, $10-20 \mathrm{~km}$ northwest of the city of Los Angeles, is one such region. In this area, multiple fault strands may rupture together in large events along the Ventura-Pitas Point fault system (Hubbard et al. 2014; McAuliffe et al. 2015; Rockwell et al. 2016). Uplifted Holocene marine terraces suggest that such earthquakes occur roughly every 400-2400 years with up to $10 \mathrm{~m}$ of uplift per event (Rockwell et al. 2016) (Fig. 1).

The geometry of the Ventura fault system is complex, with multiple segments at various angles linking together to form an irregular, kinked fault at depth. Similar geometric variations have been interpreted to have limited the shape and size of the 2015 $\mathrm{M}_{\mathrm{w}}=7.8$ Gorkha earthquake in Nepal (Wang and Fialko 2015; Hubbard et al. 2016). Thus, constraining the subsurface fault geometry may allow us to better forecast the sizes and locations of future earthquakes (Wesnousky 2006; Feng et al. 2015; Elliott et al. 2016; Hubbard et al. 2016; Qiu et al. 2016; Duan 


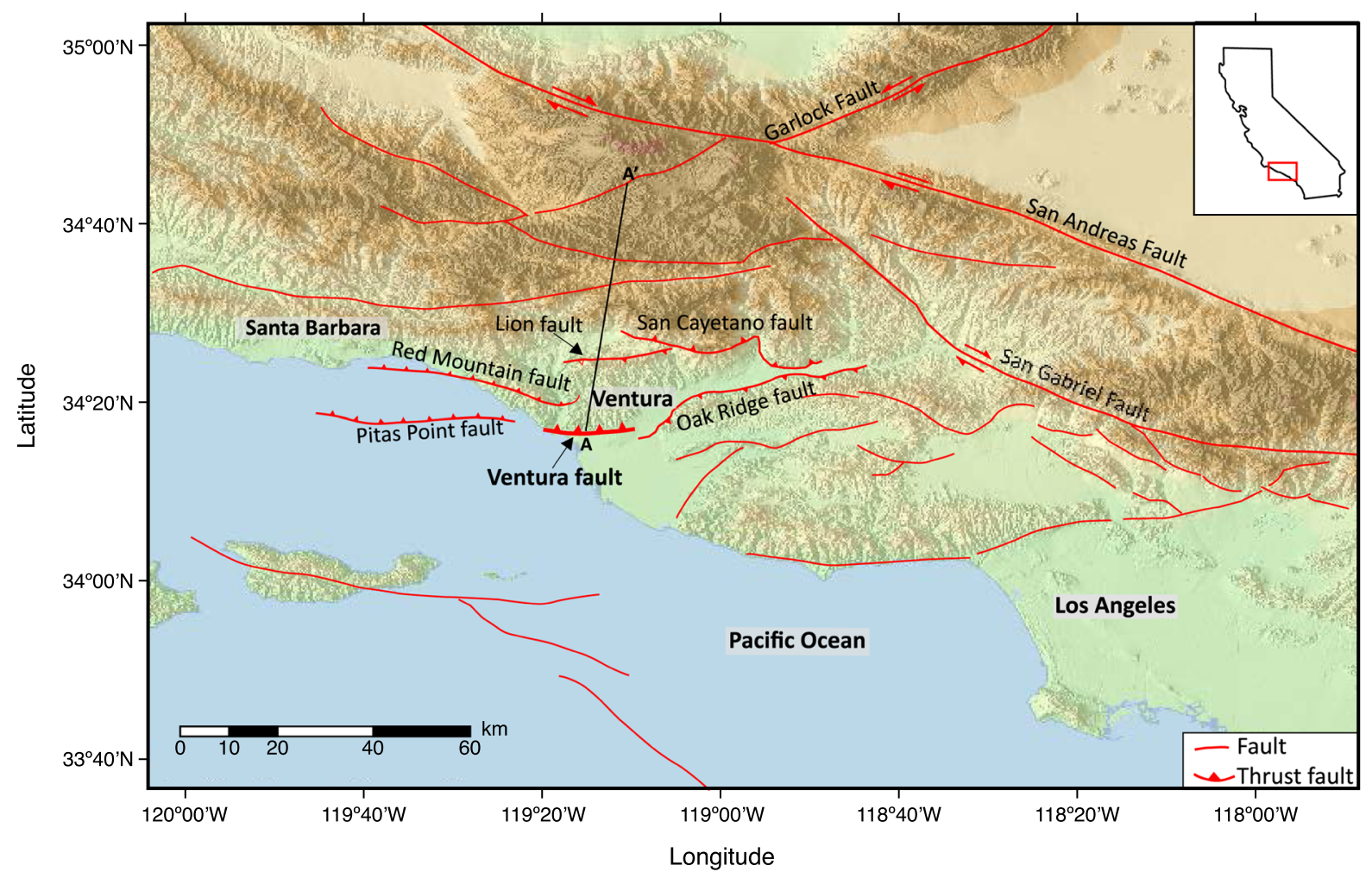

Figure 1

Map of the Ventura region and Ventura Fault in Southern California; red lines show regional faults, with teeth on the hanging wall side. $\mathrm{AA}^{\prime}$ shows cross section location of fault model. Inset shows location of this map with relationship to the borders of California

et al. 2017). However, given the sparsity of the earthquake record and the long recurrence interval of large earthquakes, such forecasts may rely in part on dynamic rupture models, to assess how geometry affects rupture (e.g., Li and Liu 2016; Qiu et al. 2016; $\mathrm{Yu}$ et al. 2018). However, these models rely on detailed descriptions of fault geometry, which can be difficult to constrain, especially in the absence of instrumented earthquakes.

The Ventura Fault system is a good target for investigating the role of fault geometry, as its geometry is constrained by seismic reflection profiles, petroleum well data, and surface geology. Although there is no instrumental record of earthquakes on this system, some information about past earthquakes has been interpreted from Holocene marine terraces. Hubbard et al. (2014) proposed that the fault can be defined by three segments: an upper ramp extending from the surface to $\sim 8 \mathrm{~km}$ depth, dipping $\sim 45^{\circ}$ to the north; this flattens onto a horizontal or sub- horizontal décollement for about $10 \mathrm{~km}$, and then steepens onto a deeper, blind ramp that reaches to $\sim 15$ to $20 \mathrm{~km}$ depth. Ryan et al. (2015) modelled dynamic rupture on a 3D Ventura fault, using a ramp-flat-ramp model modified to have a dip of $8^{\circ}$ on the décollement and wide curved hinges between the different fault segments. However, according to structural geology theory (Davis et al. 1983; Dahlen et al. 1984; Zhao et al. 1986; Dahlen 1990; Suppe 2007; Hubbard et al. 2014), the intersections between faults of different dips are typically not smooth, large-scale bends, but rather relatively narrow intersections of two kinds of faults: thrust faults dipping $\sim 20^{\circ}$ to $40^{\circ}$, and bedding-parallel décollements (usually horizontal or sub-horizontal), resulting in abrupt, angular transitions between fault segments.

Moreover, the Ventura Fault system is also a good target for investigating the role of frictional properties. A secondary aspect of the structural geology theory is that near-horizontal décollements should be 
weak compared to more steeply dipping thrust faults, due to the fact that they occur at unfavorable angles for slip (Suppe 2007; Hubbard et al. 2015). Weak fault gouges are often associated with velocitystrengthening or reduced velocity-weakening behavior (Ikari et al. 2011, 2016). Hence, we experiment with different ways of parameterizing friction, allowing for contrasting friction parameters between the décollement and thrust ramps for a suite of kinked fault-bend-fold models, inspired by the Ventura fault system (Hubbard et al. 2014). The dynamic rupture models used in this study can help to explore the frictional and stressing conditions along the fault necessary to produce realistic scenarios, including both single-segment and through-going ruptures (e.g., Biemiller and Lavier 2017).

As complex seismic cycles can result from both nonlinear frictional dynamics (Lapusta and Rice 2003; Kaneko et al. 2010; Wu and Chen 2014; Michel et al. 2017; Biemiller and Lavier 2017) and morphological gradients (Qiu et al. 2016; Romanet et al. 2018), we evaluate how varying the décollement dip and the fault curvature, as well as frictional properties along the décollement, can influence patterns of coseismic and interseismic slip. We also evaluate the effect of smoothing fault intersections to replicate the curved fault geometry studied by Ryan et al. (2015) to evaluate the sensitivity of the models to such geometric variations.

\section{Modeling Assumptions: Fault Geometry and Friction Parameters}

We simulate a time record of fault slip using the boundary integral method with the radiation damping approximation (Ben-Zion and Rice 1997; Liu and Rice 2005; Shibazaki et al. 2011; Hori and Miyazaki 2011; Qiu et al. 2016; Lambert and Barbot 2016; Goswami and Barbot 2018; Barbot 2018) in two-dimensional in-plane strain conditions. The method allows us to capture all phases of the seismic cycle, except for the radiation of seismic waves, and to include a realistic fault geometry. We properly include the effect of the free surface but we ignore the dynamic evolution of normal stress on the fault plane.
The geometry of the Ventura fault system has been studied using surface geology, seismic reflection profiles, and borehole data (Sarna-Wojcicki et al. 1976; Sarna-Wojcicki and Yerkes 1982; Hubbard et al. 2014). Following these results, we define the system as a series of three fault segments: two fault ramps dipping $40^{\circ}$ connected by a gently dipping décollement (Fig. 2a). Although Hubbard et al. (2014) suggested that the décollement is horizontal, following the dip of horizontal bedding planes, Ryan et al. (2015) modeled fault rupture using a dip of $8^{\circ}$ to represent the décollement surface. The décollement could have a slight dip, if the bedding planes are not horizontal; this geometry is common in other fault systems (e.g., the Main Himalayan Thrust in Nepal). Realistically, geological fault models will have uncertainties on décollement dip of several degrees in most cases. In order to evaluate the sensitivity of the modelling to the geometry, we tested several décollement dips $\left(0^{\circ}, 2^{\circ}, 4^{\circ}, 6^{\circ}, 8^{\circ}\right)$ to evaluate the effect on the seismic cycle (Fig. 2a). To evaluate the effect of fault smoothing, we build a series of $2 \mathrm{D}$ fault geometries with $40^{\circ}$ ramp dips and an $8^{\circ}$ décollement dip, with different amounts of curvature at the fault intersections (Fig. 2b).

To calculate fault behavior on our different fault segments, we use the framework of rate-and-state friction with the aging law, which involves a state variable that represents the effect of healing and weakening during the period of quiescence and slip (Dieterich 1978; Ruina 1983; Dieterich 2007). Rateand-state laws are capable of producing realistic models of earthquake sequences that capture the time dependence of friction, simulating a fault from its nucleation to dynamic rupture propagation, postseismic slip, interseismic period and the strengthening of the fault (Tse and Rice 1986; Lapusta et al. 2000; Daub and Carlson 2008; Barbot et al. 2012; Cubas et al. 2015; Mele Veedu and Barbot 2016; Thomas et al. 2017).

As dynamic frictional properties remain largely unknown for décollements, we explore the frictional parameters of the décollement and determine their effect on the style, magnitude, and recurrence interval of earthquake ruptures. Below $20 \mathrm{~km}$, we assume a velocity-strengthening zone (i.e., $a-b$ is positive, see Table 1), as this is approximately the depth of the 

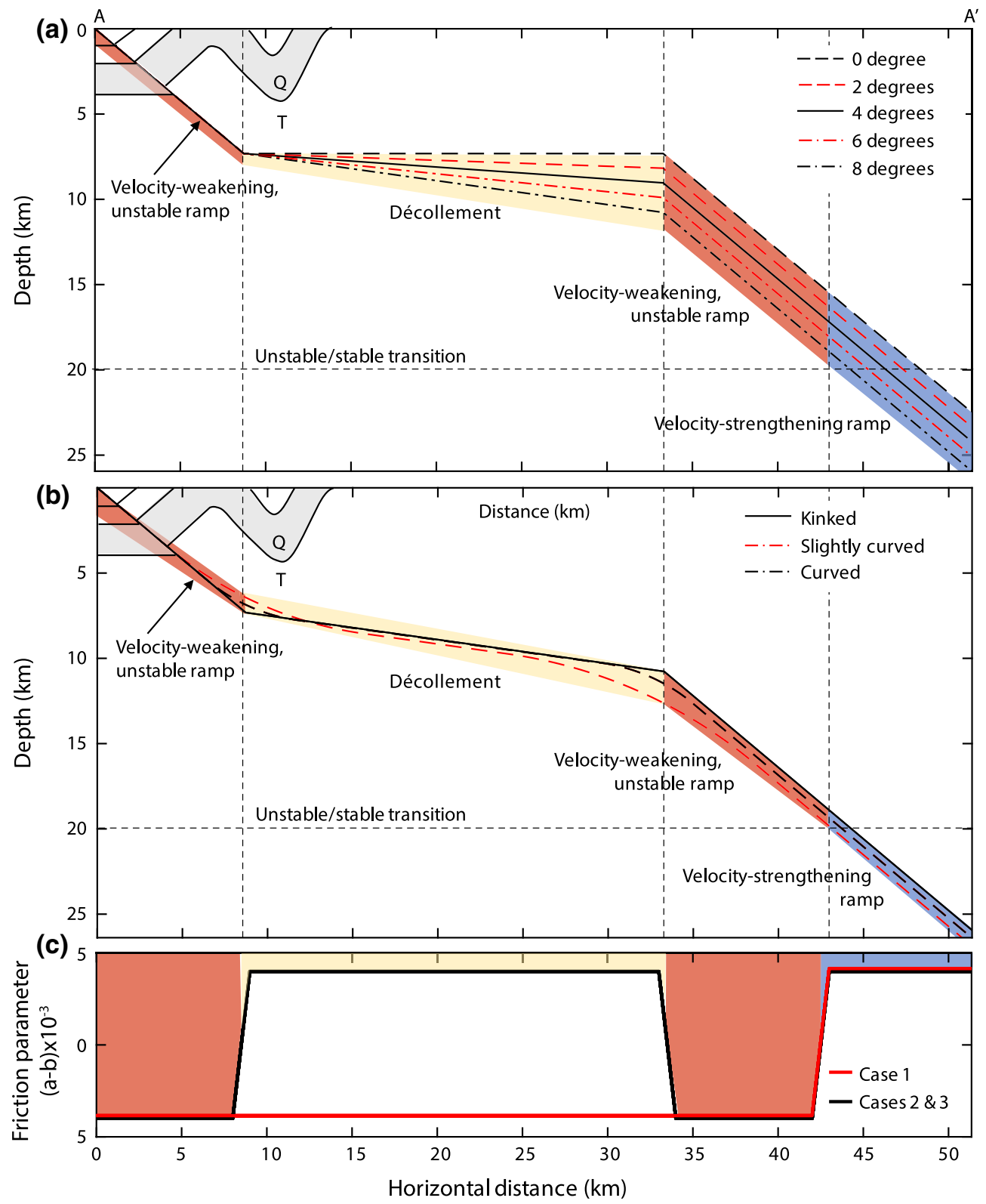

Figure 2

Simplified, two-dimensional geometry for the Ventura Thrust system along cross-section A-A' in Fig. 1. a Fault geometries considered, with the décollement dipping $0^{\circ}, 2^{\circ}, 4^{\circ}, 6^{\circ}$ and $8^{\circ}$. b Kinked versus curved fault geometry models; these use a décollement dip of $8^{\circ}$. The "Slightly Curved" model is transitional between the "kinked" and "curved" fault geometries. c Dynamic friction parameter $(a-b)$ along downdip distance of the fault for Case 1 (velocity-strengthening décollement), Case 2 (velocity-weakening, unstable décollement), and Case 3 (velocity-weakening, conditionally stable décollement). Colors along the fault geometry are used to indicate the frictional properties along the ramp or décollement, with green indicating the velocity-weakening, unstable ramp, blue indicating the velocity-strengthening region beneath the unstable to stable transition and yellow for the décollement where we vary the frictional properties between Cases 1,2 and 3 . $Q$ : Quaternary stream terrace and alluvial fan deposits close to point A, T: Tertiary sandstone and siltstone (Rockwell et al. 1984). Ventura anticline (see folded Q unit) formed due to crustal shortening above the Ventura fault (Hubbard et al. 2014)

unstable to stable transition, and below this depth the fault is expected to creep (Marone et al. 1991; Scholz 1998). In contrast, we set the ramps to have velocity- weakening behavior (negative $a-b$ values, see Table 1), so that they generate frictional instabilities when the characteristic weakening distance is small 
Table 1

Model parameters for rate-and-state friction dynamics. Plate rate is from Marshall et al. (2013)

\begin{tabular}{|c|c|c|c|c|}
\hline Frictional parameters & Symbol & $\begin{array}{l}\text { Case } 1 \\
\text { Velocity-strengthening } \\
\text { décollement }\end{array}$ & $\begin{array}{l}\text { Case } 2 \\
\text { Velocity-weakening, } \\
\text { unstable décollement }\end{array}$ & $\begin{array}{l}\text { Case } 3 \\
\text { Velocity-weakening, conditionally } \\
\text { stable décollement }\end{array}$ \\
\hline $\begin{array}{l}\text { Direct effect } \\
\text { parameter }\end{array}$ & a & $1 \times 10^{-2}$ & $1 \times 10^{-2}$ & $1 \times 10^{-2}$ \\
\hline $\begin{array}{l}\text { Evolution effect } \\
\text { parameter }\end{array}$ & $\mathrm{b}$ & $\begin{array}{l}6 \times 10^{-3} \text { along décollement } \\
\quad \text { (velocity-strengthening) } \\
1.4 \times 10^{-2} \text { above } 20 \mathrm{~km} \\
(\text { velocity-weakening) } \\
6 \times 10^{-3} \text { below } 20 \mathrm{~km} \\
\quad \text { (velocity strengthening) }\end{array}$ & $\begin{array}{l}1.4 \times 10^{-2} \text { along décollement } \\
(\text { velocity-weakening) } \\
1.4 \times 10^{-2} \text { above } 20 \mathrm{~km} \\
\quad(\text { velocity-weakening) } \\
6 \times 10^{-3} \text { below } 20 \mathrm{~km} \\
\quad(\text { velocity strengthening) }\end{array}$ & $\begin{array}{l}1.4 \times 10^{-2} \text { along décollement } \\
\quad(\text { velocity-weakening) } \\
1.4 \times 10^{-2} \text { above } 20 \mathrm{~km} \\
\quad \text { (velocity-weakening) } \\
6 \times 10^{-3} \text { below } 20 \mathrm{~km} \\
\quad \text { (velocity strengthening) }\end{array}$ \\
\hline $\begin{array}{l}\text { Characteristic } \\
\text { weakening distance }\end{array}$ & $\mathrm{L}$ & $1 \mathrm{~cm}$ & $1 \mathrm{~cm}$ & $\begin{array}{l}10 \mathrm{~cm} \text { along décollement } \\
1 \mathrm{~cm} \text { along ramps }\end{array}$ \\
\hline $\begin{array}{l}\text { Static friction } \\
\text { coefficient }\end{array}$ & $\mu_{0}$ & 0.2 & 0.2 & 0.2 \\
\hline $\begin{array}{l}\text { Reference slip } \\
\text { velocity }\end{array}$ & $\mathrm{V}_{0}$ & $10^{-6} \mathrm{~m} / \mathrm{s}$ & $10^{-6} \mathrm{~m} / \mathrm{s}$ & $10^{-6} \mathrm{~m} / \mathrm{s}$ \\
\hline Shear modulus & G & $30 \mathrm{GPa}$ & $30 \mathrm{GPa}$ & $30 \mathrm{GPa}$ \\
\hline Plate rate & $\mathrm{V}_{\mathrm{pl}}$ & $7 \mathrm{~mm} /$ year & $7 \mathrm{~mm} /$ year & $7 \mathrm{~mm} /$ year \\
\hline
\end{tabular}

enough and exhibit 'stick-slip' behavior (Ampuero and Rubin 2008; Ariyoshi et al. 2009). We test three frictional behaviors for the décollement: velocitystrengthening (Case 1), unstable velocity-weakening (Case 2), and conditionally stable velocity-weakening (Case 3). In Case 1, the décollement should impede earthquake-style slip, while in Case 2, it should encourage it. In Case 3, the décollement has velocityweakening properties but a large characteristic weakening distance, which is expected to result in a mixture of stick-slip and creep behavior. We change the characteristic weakening distance by a factor of 10 to place the décollement firmly into the stableweakening regime.

Numerical studies indicate that complex seismic cycles with full and partial ruptures of the seismogenic zone along a uniform fault occur for large values of the ratio of $R / h^{*}$, where $R$ is the length of the fault and $h^{*}$ is the nucleation size (Kato 2003, 2014; Lapusta and Rice 2003; Gabriel et al. 2012; Wu and Chen 2014; Michel et al. 2017). A smaller $L$ represents a smaller critical nucleation size and hence the ability to produce smaller earthquakes, resulting in a wider range of earthquake magnitudes with increasing complexity. Here, we use a $R / h^{*}$ ratio as high as approximately 50 in the unstable weakening case (Case 2).

For all models, we evaluate the dynamics of fault slip numerically for a period of 10,000 years to determine the resulting fault slip patterns. Outputs include slip amounts, recurrence intervals, earthquake magnitudes, and stress drop, which refers to the difference between the initial and final shear stress and is approximately 1-10 MPa for natural earthquakes (Brune 1970). The amount of fault slip in a given earthquake and the recurrence interval between seismic events depend on the frictional parameters $(a-b)$, the effective normal stress $\bar{\sigma}$, characteristic weakening distance, $L$, and the rupture size (e.g., Tse and Rice 1986; Lapusta and Rice 2003, Liu and Rice 2005, 2007, 2009; Ikari et al. 2011; Barbot et al. 2012; Lapusta and Barbot 2012; Ikari et al. 2016). Earthquake magnitude is empirically related to the length of the fault patch and the average amount of slip on the patch, as follows (Biasi and Weldon 2006):

$$
M_{w}=6.92+1.14 \log _{10}(s),
$$

where $\mathrm{s}$ is the average fault slip during a seismic event.

Table 1 summarizes the parameters for the three frictional cases described above. To ensure that our model produces plausible slip amounts, we varied the effective normal stress, $\bar{\sigma}$, for each fault geometry and frictional case, testing 100 and $200 \mathrm{MPa}$. This range of effective normal stress is typical for models of this type (e.g., Tse and Rice 1986; Segall 2012; Qiu et al. 2016). In all models, we load the fault at a 
constant rate of $\mathrm{V}_{1}=7 \mathrm{~mm} / \mathrm{year}$ west-northwest, compatible with the rate of contraction across the Ventura region from GPS data (Marshall et al. 2013).

\section{Impact of Friction and Geometry on the Seismic Cycle}

We compare the predictions resulting from our models to the paleoseismic interpretations of the Ventura Thrust system (Hubbard et al. 2014; Rockwell et al. 2016), which suggest that ruptures should be capable of breaking through the décollement and causing slip on all three segments in a single event. However, when we explore décollement behavior in other parts of the world, we note that these faults display variable behavior. Thus, when we evaluate the results of our modeling, we are looking for not just behavior that can match the interpreted multisegment ruptures of the Ventura fault but also behavior consistent with earthquakes on other systems. Recorded earthquakes in which we can observe both the geometry and slip patterns on décollements are rare, but they do exist. In the $1999 \mathrm{M}_{\mathrm{w}}=7.3$ Chi-Chi, Taiwan earthquake, the Chelungpu-Sanyi thrust system produced 3-10 $\mathrm{m}$ of slip at the surface, activating both the ramp and the frontal part of the décollement at 5-8 km depth (Lee and Ma 2000; Yu et al. 2001; Johnson et al. 2001; Yue et al. 2005; Rousset et al. 2012). In the $2015 \mathrm{M}_{\mathrm{w}}=7.8$ Gorkha earthquake, Nepal, most of the slip was limited to a patch of décollement, decreasing to zero along the surrounding ramps (Diao et al. 2015; Bai et al. 2016; Hubbard et al. 2016; Sreejith et al. 2016; Qiu et al. 2016). This event is only one example of how coseismic slip can occur on this fault system. Paleoseismological evidence suggests that previous ruptures have also propagated to the surface, resulting in larger magnitude earthquakes (Bilham et al. 2001; Lavé et al. 2005; Sapkota et al. 2013; Bollinger et al. 2016). We therefore expect that if dynamic rupture models are properly representing realistic physical parameters, they should exhibit multiple styles of earthquakes: décollement-only, ramp and décollement together, and through-going events.
The three sets of frictional parameters that we test produce different earthquake rupture behaviors (Fig. 3). In Case 1 (velocity-strengthening décollement), slip along the décollement occurs primarily as creep, with partial ruptures that either nucleate at the bottom and propagate updip to the décollement, or nucleate at the top of the décollement and rupture in both directions, either partially or to the surface (Fig. 3, Case 1). In Case 2 (velocity-weakening, unstable décollement), partial ruptures occur with occasional larger through-going ruptures (Fig. 3, Case 2). All of the earthquakes nucleate either at the top or bottom of the décollement, where there is a change in orientation of the fault. Patches can undergo full locking, creep and coseismic slip during different periods of the earthquake cycle, similar to models of fault slip evolution by Noda and Lapusta (2013) and Noda and Hori (2014), suggesting that the same segment may experience creep, slow slip, and seismic ruptures during different periods over many earthquake cycles. Lastly, in Case 3, the velocityweakening, conditionally stable décollement creeps during the interseismic period; earthquakes that occur at depth mostly stop at the décollement, as stresses on the décollement have already been partially released through creeping behavior (Fig. 3, Case 3). This continues until a larger through-going rupture occurs.

We compare the simulated earthquakes that we generate with the characteristics of the paleoseismic catalogue for the Ventura fault (Rockwell et al. 2016). We discard models that produce a recurrence time of large, through-going earthquake greater than $2.4 \mathrm{kyr}$ or lower than 400 years, and those that produce seismic slip amplitudes near the surface greater that $11 \mathrm{~m}$ or lower than $4 \mathrm{~m}$ (Fig. 4). Although our goal is to observe variations due to fault geometry and frictional properties, the effective normal stress exerts significant control on slip amount and recurrence intervals. An increase from 100 to $200 \mathrm{MPa}$ along the fault results in an approximate doubling of slip amount and recurrence interval for all frictional parameters and dip angles (Fig. 4). We therefore recognize that each physical parameter cannot be effectively constrained simply by comparing with the paleoseismic record, and we focus our analysis on three end-member models with large $R / h *$ ratios that broadly reproduce the variability of recurrence times 

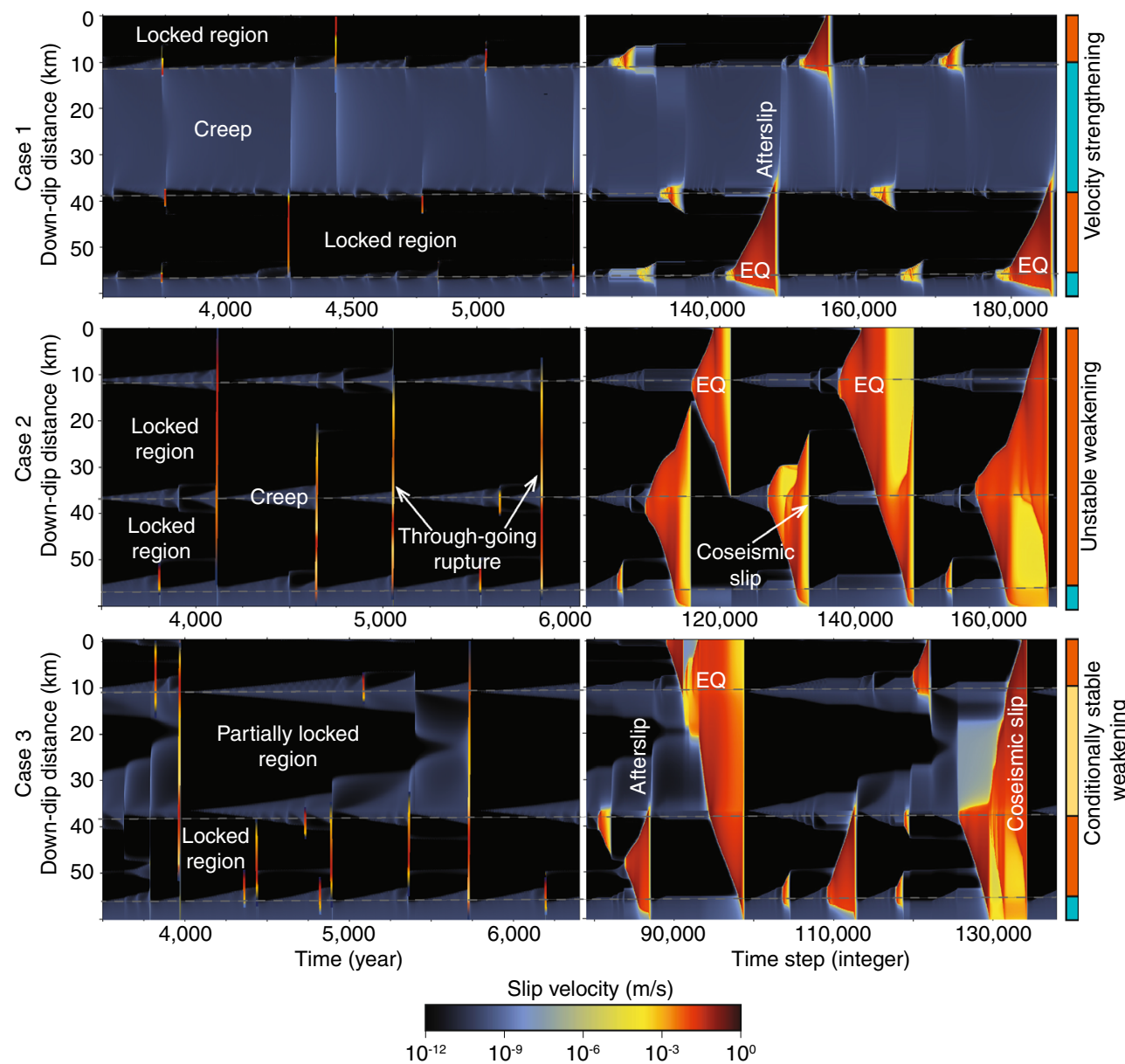

Figure 3

Earthquake cycles for the three sets of frictional parameters on the décollement (décollement dip $0^{\circ}$ ); the right column with colored boxes represent the dynamic frictional parameters along the fault. a Case 1 (velocity-strengthening décollement): the décollement only undergoes creep and afterslip. b Case 2 (velocity-weakening, unstable décollement): the décollement exhibits full locking and creep (dark blue) at different times in the earthquake cycle and participates in partial and through-going ruptures. c Case 3 (velocity-weakening, conditionally stable décollement); the décollement exhibits full locking and creep, and participates in through-going but not partial ruptures; through-going ruptures are less frequent than in Case 2

and slip amplitude near the fault trace, with complex (non-characteristic) earthquake sequences.

\subsection{Sensitivity of Models to Variations in Décollement Dip}

Figure 5 compares the seismic cycles obtained for décollement dips of $0^{\circ}$ and $8^{\circ}$ for Case 3 (velocityweakening, conditionally stable décollement). The details of the earthquake sequence produced in the two cases are different, including the number of small earthquakes on the deep ramp and the earthquake size. However, the overall pattern of alternating partial and full thrust ruptures is similar, and the average amplitude of slip and recurrence times for the earthquakes that break the surface are comparable (Table 2). In other words, varying the dip from $0^{\circ}$ to $8^{\circ}$ leads to only mild variations in average earthquake slip amounts and recurrence intervals, despite more significant changes in the pattern of small earthquakes at depth. These results indicate that surface slip measured through paleoseismic techniques near the fault tip have its limitations and may have missed small earthquakes that are confined to the deeper ramp and did not produce slip in the shallow trench. 
(a)

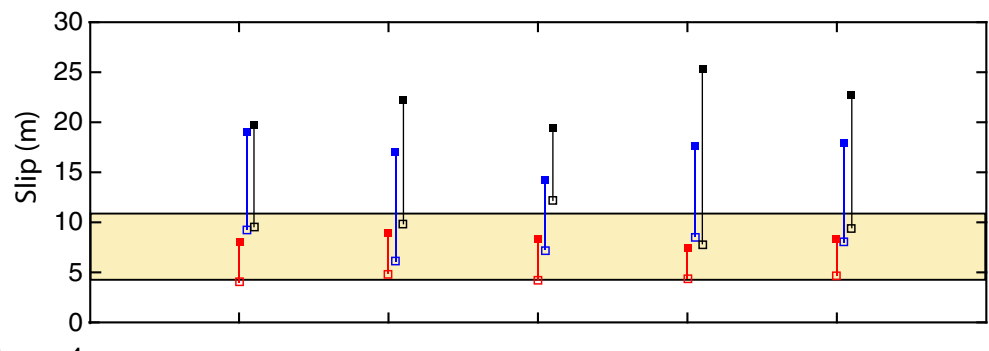

Case $1 \uparrow$

- Case $2100 \mathrm{MPa}$

- Case 3

- Case $1 \uparrow$

- Case 2 200 MPa

(b)

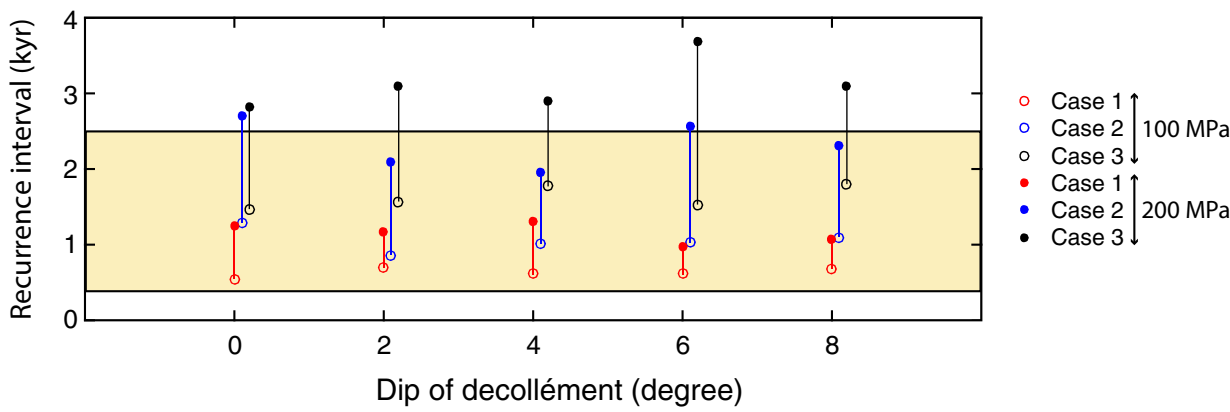

Figure 4

Plots of slip and recurrence interval for all décollement dip angles at effective normal stress levels of $100 \mathrm{MPa}$ and $200 \mathrm{MPa}$ (represented by the unfilled and filled markers respectively). Yellow shaded area represent range of slip amounts and recurrence intervals for the Ventura fault from paleoseismic records (Hubbard et al. 2014; Rockwell et al. 2016). The slip and recurrence interval values vary by approximately $20 \%$ across the $0^{\circ}-8^{\circ}$ dips for any given frictional case, but there is no clear pattern to this variation

(a) Flat décollement

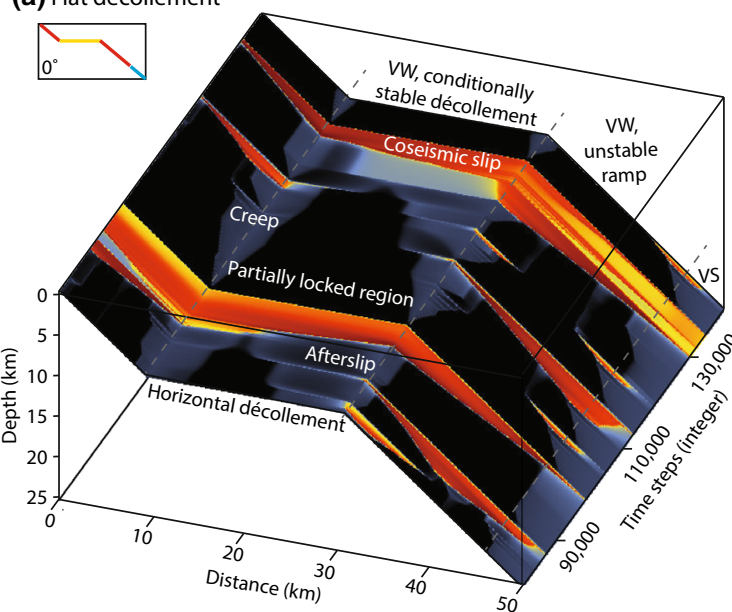

(b) Dipping décollement

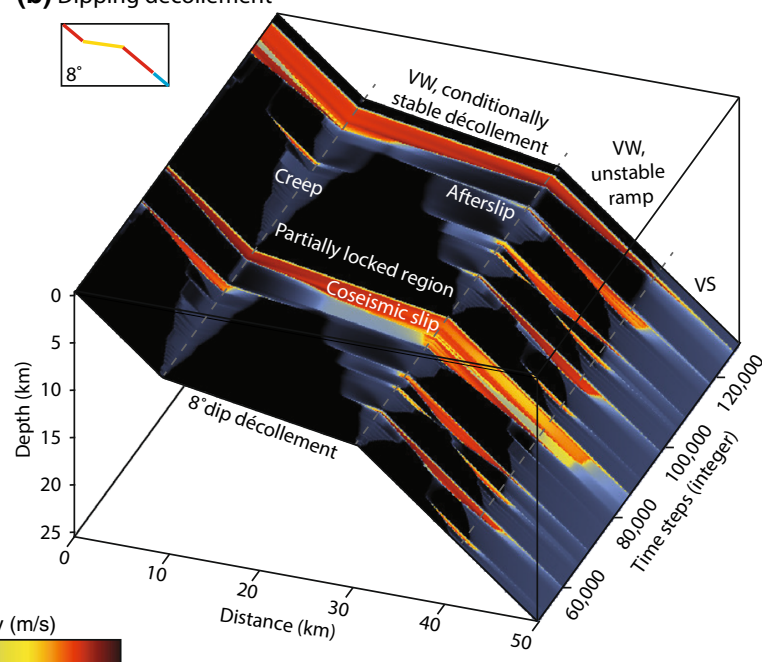

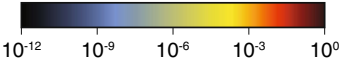

Figure 5

Seismic cycle over 10,000 years for Case 3 (velocity weakening (VW), conditionally stable décollement) for a décollement with dip of a $0^{\circ}$ and $\mathbf{b} 8^{\circ}$. The $\mathrm{x}$-axis indicates the horizontal distance from the surface trace. The y-axis indicates the computational time steps in the simulation, which emphasizes periods when the slip velocity is high. The vertical axis is depth below the surface trace of the fault. The colors describe the slip velocity: dark colors indicate fault locking, warm colors indicate seismic slip, and dark blue represents fault creep. Both models show a complex seismic cycle with full and partial ruptures, small earthquakes clustering near the fault bends and near the bottom of the seismogenic zone, and occasional creep near the fault bends. While the seismic cycles are different, the average slip and recurrence intervals of earthquakes that rupture to the surface are comparable (Table 2) 
Table 2

Slip and recurrence intervals for five fault geometries under Case 3 (velocity weakening, conditionally stable décollement), for $\bar{\sigma}=100 \mathrm{MPa}$

\begin{tabular}{llccr}
\hline Fault geometry & Range of fault slip $(\mathrm{m})$ & Range of recurrence intervals (year) & Average fault slip (m) & Recurrence interval (year) \\
\hline $0^{\circ}$ & Large events: $7-12$ & $1260-1800$ & 9.5 & 1470 \\
& Small events: $3.4-4.5$ & $300-480$ & 3.8 & 370 \\
$2^{\circ}$ & Large events: $7.4-11.6$ & $1430-1700$ & 9.8 & 1570 \\
& Small events: $3.7-5.0$ & $100-280$ & 4.4 & 190 \\
$4^{\circ}$ & Large events: $9.5-11.3$ & $1450-1620$ & 11.0 & 290 \\
& Small events: $0.6-1.6$ & $260-300$ & 1.0 & 1500 \\
$6^{\circ}$ & Large events: $7.4-8.3$ & $1510-1540$ & 7.8 & 240 \\
$8^{\circ}$ & Small events: $3.9-4.2$ & $210-250$ & 4.1 & 1800 \\
& Large events: $8.0-11.3$ & $1720-1840$ & 9.4 & 3.4 \\
\hline
\end{tabular}

Large and small slip events occur in the form of partial and through-going ruptures. Large events have longer recurrence intervals compared to small events

For all dip angles considered for Case 3 (velocity weakening, conditionally stable décollement), two types of characteristic earthquakes occur: large, through-going ruptures, and smaller ruptures confined to a single segment. Although the earthquake details vary, there is no clear dependence on the dip angle, and the slip and recurrence interval values for the largest earthquakes are within $\sim 20 \%$ of each other (Table 2). The average fault slip for the small events shows more variability, but as these events may not be detected by paleoseismological studies, we do not consider them during model selection.

\subsection{Effect of Frictional Parameters on Earthquake Rupture Patterns}

Compared to the dip of the décollement, the frictional parameters exert significantly more influence on the slip patterns. We investigate the effect of the three frictional cases on the range of slip and recurrence intervals (Fig. 4) and the patterns of earthquake rupture that occur across the rampdécollement system (Fig. 3).

In Case 1 (velocity-strengthening décollement), most of the slip on the décollement is aseismic, with long-term creep and postseismic periods of accelerated slip. Earthquakes are limited to smaller events that rupture partially either below or above the décollement, with no through-going ruptures (Fig. 3, Case 1). In contrast, a velocity-weakening décollement (Cases 2 and 3) produces earthquake ruptures of much greater complexity, with both partial and through-going ruptures. These larger, through-going ruptures are more consistent with the behavior interpreted for the Ventura fault system.

In Case 2 (velocity-weakening, unstable décollement), earthquakes generally start at the fault bends and rupture in both directions. These earthquakes often propagate through the décollement and then either stop at the next fault bend (updip or downdip), or propagate across the second fault bend as well, resulting in a through-going rupture. Most of the fault system is locked between earthquakes, although there is a small amount of creep centered around the fault bends. Small earthquakes occasionally nucleate at the bottom of the velocity-weakening region. In Case 3 (velocity-weakening, conditionally stable décollement), the décollement creeps part of the time. This relieves some of the stresses on the décollement, which consequently participates in fewer earthquakes. Earthquakes nucleate on the ramps and either stop at the bends or rupture all the way through. Unlike Case 2, there are no partial earthquakes that rupture the décollement. 


\subsection{Effect of Fault Curvature}

We investigate whether the degree of curvature at the fault bend impacts the seismic cycle significantly. To do this, we run all three frictional cases for our curved and kinked fault geometries, and observe the differences in the earthquake cycles and types of earthquakes produced (Fig. 6). In the kinked fault geometry, smaller earthquakes occur on the upper ramp, with some additional earthquakes occurring at shallow depths close to the first kink or at the lower kink between the décollement and the lower ramp (Fig. 6a). In contrast, the curved fault geometry shows earthquakes nucleating at the transition zone between the velocity-weakening and velocitystrengthening zones at $20 \mathrm{~km}$ depth; these earthquakes either propagate throughout the fault and break at the surface, or cause partial ruptures of the lower ramp and/or décollement (Fig. 6b). However, the overall earthquake patterns are generally similar. We conclude that the modeling is generally insensitive to the curvature of the fault bends with regards to earthquake style.
Despite this overall similarity, there is a measurable difference between the two geometries. Everything else being the same, the curved model produces larger earthquakes following longer interseismic periods. For example, for an input stress of $100 \mathrm{MPa}$ and with Case 3 (velocity-weakening, conditionally stable décollement), the kinked fault produces events with $12 \mathrm{~m}$ of slip every 1720-1860 years, compared to 15-16 m of slip every 2140-2270 years for the curved fault geometry (Table 3). Thus, if geological faults are truly kinked, using a curved fault geometry for modeling might result in an over-estimate of slip and recurrence interval (Fig. 6). However, as shown in the previous figures, the effective confining pressure has a similar effect and therefore these parameters trade off with each other. Because we do not have strong constraints on the physical parameters of the fault geometry, we conclude that we cannot use this effect to distinguish between fault geometries.

We also note that for Case 3, the kinked geometry produces significantly more creep on the décollement (a)

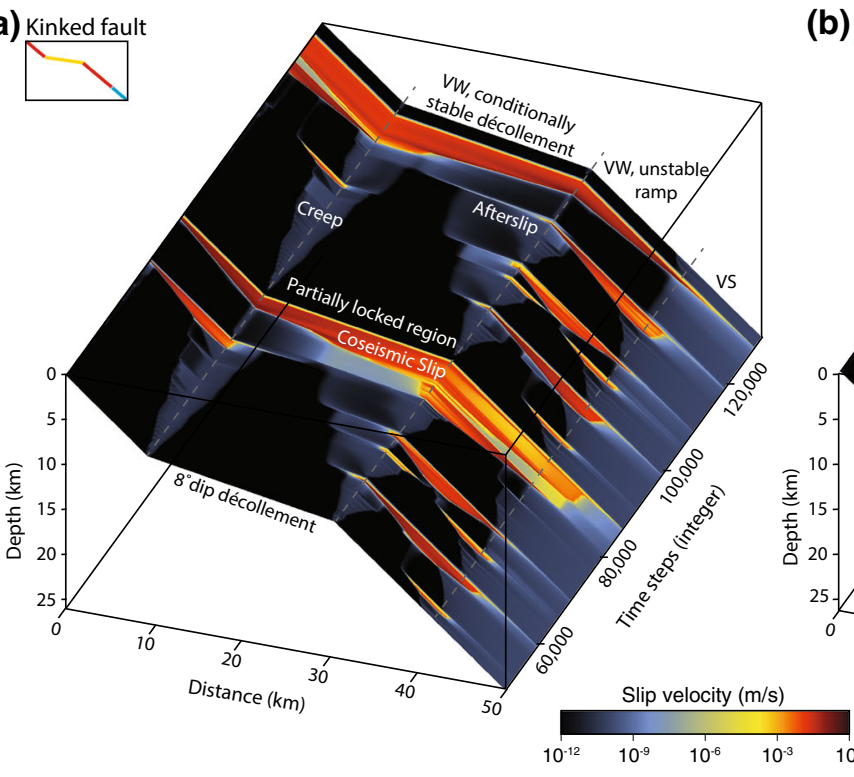

(b) Curved fault

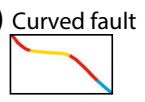

Figure 6

Seismic cycle simulations for a kinked versus b curved fault geometries for case 3 (velocity weakening (VW), conditionally stable décollement) and a décollement at $8^{\circ}$ dip. Velocity-strengthening (VS) regions display continuous creep at depths below $20 \mathrm{~km}$. The $\mathrm{x}$-axis indicates the horizontal distance from the surface trace. The $\mathrm{y}$-axis indicates the computational time steps in the simulation. The vertical axis is depth. Earthquake cycles are generally similar, with more creep on the upper ramp in the kinked fault geometry. The amount of slip and recurrence intervals vary by $\sim 20 \%$, with the kinked geometry exhibiting slightly smaller, more frequent events (Table 3 ) while the curved geometry exhibits more frequent and higher magnitude earthquakes 
Table 3

Comparison of slip and recurrence intervals for the kinked, slightly curved and curved fault geometries for Case 3 (velocity weakening, conditionally stable décollement)

\begin{tabular}{llll}
\hline Fault geometry & Fault slip amount $(\mathrm{m})$ & Recurrence interval range (year) & Stress drop (MPa) \\
\hline Kinked & Large event: $12.0-12.2$ & $1720-1860$ & $6.8-7.9$ \\
& Small event: 4.2 & $50-110$ years before large event & \\
Slightly curved & Large event: 15.5 & 2270 & $6-7$ \\
& Small event: $1-2$ & $380-500$ & \\
More curved & Large event: 16 & $2140-2270$ & 10 \\
& Small event: 3 & $87-900$ & \\
\hline
\end{tabular}

The curved geometry produces events with larger amounts of slip and longer recurrence intervals compared to the kinked fault geometry. Stress drop is higher in the curved fault geometry

than the curved fault geometry (Fig. 6). The creep at the kinks helps to relieve the stress that builds up during the interseismic period. This may explain why there is less stress drop in earthquakes on the kinked fault geometry (6.8-7.9 MPa) compared to the curved geometry (10 MPa). However, the overall patterns are similar for the two geometries, and both can provide an acceptable fit to paleoseismic records.

\section{Discussion and Conclusion}

In this study, we adopt a two-dimensional model of the Ventura Thrust system to assess the sensitivity of dynamic earthquake models to changes in geometry and frictional properties of a ramp/décollement system. We compare the modeled slip at the top of the superficial ramp to slip inferred from observations of uplifted Holocene marine terraces associated with the Ventura fault. By testing three frictional parameterizations for the décollement (Case 1-velocitystrengthening; Case 2-unstable velocity-weakening, and Case 3-conditionally stable velocity-weakening), we evaluate which frictional parameters produce a better representation of the paleoseismic record along this fault. This paleoseismic record indicates that the Ventura fault likely ruptures periodically in large, through-going ruptures (Hubbard et al. 2014), and therefore models that produce only smaller single-segment ruptures are unlikely to properly represent the physics of the system.
Our results show that varying the fault geometry (décollement dip from $0^{\circ}$ to $8^{\circ}$, and curvature of the fault bends) leads to small variations in earthquake cycles in terms of the rupture extent, the amount of slip and the recurrence intervals for small and large earthquakes. Changing the dip does not affect the overall earthquake rupture patterns, although slip amounts and recurrence intervals vary within $20 \%$ of each other. Changing the curvature of the fault bends results in relatively small differences in slip amounts and recurrence intervals, without significantly altering the earthquake rupture pattern as a whole. We conclude that a curved fault geometry can reasonably be used to simplify a model to allow for smoother rupture propagation and ground deformation. However, this may lead to an overestimation of slip amounts and recurrence intervals if the fault is truly kinked.

In contrast, the effective normal stress and frictional properties significantly affect the modeled slip patterns. Slip in earthquakes approximately doubles when the effective normal stress is increased from 100 to $200 \mathrm{MPa}$, with a corresponding doubling of recurrence intervals for all cases tested. Varying the friction changes the recurrence intervals and magnitude of slip, with earthquake slip of approximately $5 \mathrm{~m}$ for Case 1 (velocity-strengthening), compared to a combination of two earthquake types (large events with 7-20 m slip and small events with $4 \mathrm{~m}$ slip for Cases 2 and 3). Table S1 presents the differences in earthquake slip and recurrence intervals for the five 
fault geometries and three sets of frictional parameters that we tested.

Overall, because the model results are not overly sensitive to small changes in fault geometry, we conclude that fault geometries constrained by geological measurements, like the Ventura fault geometry, are likely sufficient to inform physicsbased numerical models, without the concern that a small change in geometry will lead to significant differences in slip behavior. However, there are major uncertainties that do significantly alter the model outcome. Specifically, the effective normal stress is not well known, limiting the utility of rupture models. In addition, the friction, which depends directly on the fault geometry (thrust ramp versus décollement), is not known. However, with further studies it may be possible to constrain the friction parameters of different fault types based on known rupture histories. For instance, here we observe that one set of frictional parameters does not replicate the known behavior of the Ventura fault system: Case 1 produces only smaller earthquakes that rupture only the updip or downdip ramp; no rupture is capable of crossing the décollement. This is inconsistent with the geological record, which suggests larger, throughgoing ruptures. Within the limits of this two-dimensional study, we interpret that it is inappropriate to model the décollement as velocity-strengthening. Cases 2 and 3 remain possible, as they are capable of producing both partial and through-going ruptures.

We expect that the frictional behavior of fault ramps and décollements should have broad applicability, and as such it may be useful to study similar fault geometries in other settings. For instance, the $1999 \mathrm{M}_{\mathrm{w}}=7.6 \mathrm{Chi}-\mathrm{Chi}$ earthquake in Taiwan was the result of slip on the Chelungpu thrust and part of the downdip décollement; such events can be reasonably replicated with all three of our friction parameterizations (Dominguez et al. 2003; Yue et al. 2005; Rousset et al. 2012). In contrast, the 2015 $\mathrm{M}_{\mathrm{w}}=7.8$ Gorkha earthquake in Nepal initiated at a downdip fault bend, with slip almost entirely propagating updip onto the décollement; there was no significant slip on ramps (Diao et al. 2015; Bai et al. 2016; Hubbard et al. 2016, Sreejith et al. 2016). In our modeling, all earthquakes involve significant ramp slip; we therefore do not reproduce such behavior. This slip pattern indicates that either we are not properly representing the frictional fault behavior, and/or that the geometric or geological differences between the Gorkha and Ventura systems (e.g., depth, dip angle, 3D effects) produce different results.

Our study, which combines fault geometry, frictional parameters, slip modeling, and geological observations, is an important step towards the development of future realistic rupture scenarios. However, reaching this goal will require considerable work in evaluating how friction depends on fault type, as well as the inclusion of three dimensional variations and interactions among fault segments (e.g., Li and Liu 2016; Yu et al. 2018). Some of the largest variations in dynamic rupture models still come from properties that are not well known, such as the frictional properties of décollements and appropriate values for effective normal stress. Ultimately, accurate modelling of earthquake dynamics for potential earthquake forecasting may help mitigate the consequences of earthquakes on the affected communities.

\section{Acknowledgements}

This work comprises Earth Observatory of Singapore contribution no. 200. This research is supported by the National Research Foundation of Singapore under the NRF Fellowship scheme (National Research Fellow Awards no. NRF-NRFF2013-04 and no. NRF-NRFF2013-06) and by the Earth Observatory of Singapore, the National Research Foundation, and the Singapore Ministry of Education under the Research Centres of Excellence initiative.

Open Access This article is distributed under the terms of the Creative Commons Attribution 4.0 International License (http:// creativecommons.org/licenses/by/4.0/), which permits unrestricted use, distribution, and reproduction in any medium, provided you give appropriate credit to the original author(s) and the source, provide a link to the Creative Commons license, and indicate if changes were made.

Publisher's Note Springer Nature remains neutral with regard to jurisdictional claims in published maps and institutional affiliations. 


\section{REFERENCES}

Ampuero, J. P., \& Rubin, A. M. (2008). Earthquake nucleation on rate and state faults-aging and slip laws. Journal of Geophysical Research Solid Earth, 113, B1.

Anderson, G., Aagaard, B., \& Hudnut, K. (2003). Fault interactions and large complex earthquakes in the Los Angeles area. Science, 302(5652), 1946-1949.

Ariyoshi, K., Matsuzawa, T., Yabe, Y., Kato, N., Hino, R., Hasegawa, A., et al. (2009). Character of slip and stress due to interaction between fault segments along the dip direction of a subduction zone. Journal of Geodynamics, 48(2), 55-67.

Bai, L., Liu, H., Ritsema, J., Mori, J., Zhang, T., Ishikawa, Y., et al. (2016). Faulting structure above the Main Himalayan Thrust as shown by relocated aftershocks of the $2015 \mathrm{M}_{\mathrm{w}} 7.8$ Gorkha, Nepal, earthquake. Geophysical Research Letters, 43(2), 637-642.

Barbot, S. D. (2018). Asthenosphere flow modulated by megathrust earthquake cycles. Geophysical Research Letters, 2015, 45.

Barbot, S., Lapusta, N., \& Avouac, J. P. (2012). Under the hood of the earthquake machine: Toward predictive modeling of the seismic cycle. Science, 336(6082), 707-710.

Ben-Zion, Y., \& Rice, J. R. (1997). Dynamic simulations of slip on a smooth fault in an elastic solid. Journal of Geophysical Research Solid Earth, 102(B8), 17771-17784.

Biasi, G. P., \& Weldon, R. J. (2006). Estimating surface rupture length and magnitude of paleoearthquakes from point measurements of rupture displacement. Bulletin of the Seismological Society of America, 96(5), 1612-1623.

Biemiller, J., \& Lavier, L. (2017). Earthquake supercycles as part of a spectrum of normal fault slip styles. Journal of Geophysical Research Solid Earth, 122(4), 3221-3240.

Bilham, R., Gaur, V. K., \& Molnar, P. (2001). Himalayan seismic hazard. Science, 293(5534), 1442-1444.

Bollinger, L., Tapponnier, P., Sapkota, S. N., \& Klinger, Y. (2016). Slip deficit in central Nepal: Omen for a repeat of the 1344 AD earthquake? Earth Planets and Space, 68(1), 12.

Brune, J. N. (1970). Tectonic stress and the spectra of seismic shear waves from earthquakes. Journal of Geophysical Research, 75(26), 4997-5009.

Cubas, N., Lapusta, N., Avouac, J. P., \& Perfettini, H. (2015). Numerical modeling of long-term earthquake sequences on the NE Japan megathrust: Comparison with observations and implications for fault friction. Earth and Planetary Science Letters, 419, 187-198.

Dahlen, F. A. (1990). Critical taper model of fold-and-thrust belts and accretionary wedges. Annual Review of Earth and Planetary Sciences, 18(1), 55-99.

Dahlen, F. A., Suppe, J., \& Davis, D. (1984). Mechanics of foldand-thrust belts and accretionary wedges: Cohesive Coulomb theory. Journal of Geophysical Research Solid Earth, 89(B12), 10087-10101.

Daout, S., Barbot, S., Peltzer, G., Doin, M. P., Liu, Z., \& Jolivet, R. (2016). Constraining the kinematics of metropolitan Los Angeles faults with a slip-partitioning model. Geophysical Research Letters, 43, 21.

Daub, E. G., \& Carlson, J. M. (2008). A constitutive model for fault gouge deformation in dynamic rupture simulations. Journal of Geophysical Research Solid Earth, 113, B12.
Davis, T. L., \& Namson, J. S. (1994). A balanced cross-section of the 1994 Northridge earthquake, southern California. Nature, 372(6502), 167.

Davis, D., Suppe, J., \& Dahlen, F. A. (1983). Mechanics of foldand-thrust belts and accretionary wedges. Journal of Geophysical Research Solid Earth, 88(B2), 1153-1172.

Diao, F., Walter, T. R., Motagh, M., Prats-Iraola, P., Wang, R., \& Samsonov, S. V. (2015). The 2015 Gorkha earthquake investigated from radar satellites: Slip and stress modeling along the MHT. Frontiers in Earth Science, 3, 65.

Dieterich, J. H. (1978). Time-dependent friction and the mechanics of stick-slip. Pure and Applied Geophysics, 116(4-5), 790-806.

Dieterich, J. H. (2007). Applications of rate-and state-dependent friction to models of fault slip and earthquake occurrence-4.04.

Dolan, J. F., \& Rockwell, T. K. (2001). Paleoseismologic evidence for a very large $\left(M_{w}>7\right)$, post-AD 1660 surface rupture on the Eastern San Cayetano Fault, Ventura County, California: Was this the elusive source of the damaging 21 December 1812 Earthquake? Bulletin of the Seismological Society of America, 91(6), 1417-1432.

Dominguez, S., Avouac, J. P., \& Michel, R. (2003). Horizontal coseismic deformation of the 1999 Chi-Chi earthquake measured from SPOT satellite images: Implications for the seismic cycle along the western foothills of central Taiwan. Journal of Geophysical Research Solid Earth, 108, B2.

Duan, B., Liu, D., \& Yin, A. (2017). Seismic shaking in the North China Basin expected from ruptures of a possible seismic gap. Geophysical Research Letters, 44(10), 4855-4862.

Elliott, J. R., Jolivet, R., González, P. J., Avouac, J. P., Hollingsworth, J., Searle, M. P., et al. (2016). Himalayan megathrust geometry and relation to topography revealed by the Gorkha earthquake. Nature Geoscience, 9(2), 174.

Feng, G., Li, Z., Shan, X., Zhang, L., Zhang, G., \& Zhu, J. (2015). Geodetic model of the 2015 April $25 \mathrm{M}_{\mathrm{w}} 7.8$ Gorkha Nepal Earthquake and $\mathrm{M}_{\mathrm{w}} 7.3$ aftershock estimated from InSAR and GPS data. Geophysical journal international, 203(2), 896-900.

Gabriel, A. A., Ampuero, J. P., Dalguer, L. A., \& Mai, P. M. (2012). The transition of dynamic rupture styles in elastic media under velocity-weakening friction. Journal of Geophysical Research Solid Earth, 117, B9.

Goswami, A., \& Barbot, S. (2018). Slow-slip events in semi-brittle serpentinite fault zones. Scientific Reports, 8(1), 6181.

Hauksson, E., Jones, L. M., \& Hutton, K. (1995). The 1994 Northridge earthquake sequence in California: Seismological and tectonic aspects. Journal of Geophysical Research Solid Earth, 100(B7), 12335-12355.

Hori, T., \& Miyazaki, S. I. (2011). A possible mechanism of M 9 earthquake generation cycles in the area of repeating $M$ 7-8 earthquakes surrounded by aseismic sliding. Earth Planets and Space, 63(7), 48.

Hubbard, J., Almeida, R., Foster, A., Sapkota, S. N., Bürgi, P., \& Tapponnier, P. (2016). Structural segmentation controlled the $2015 \mathrm{M}_{\mathrm{w}} 7.8$ Gorkha earthquake rupture in Nepal. Geology, 44(8), 639-642.

Hubbard, J., Barbot, S., Hill, E. M., \& Tapponnier, P. (2015). Coseismic slip on shallow décollement megathrusts: Implications for seismic and tsunami hazard. Earth-Science Reviews, 141, 45-55.

Hubbard, J., Shaw, J. H., Dolan, J., Pratt, T. L., McAuliffe, L., \& Rockwell, T. K. (2014). Structure and seismic hazard of the Ventura Avenue Anticline and Ventura Fault, California: 
Prospect for large, multisegment ruptures in the Western Transverse Ranges. Bulletin of the Seismological Society of America, 104(3), 1070. https://doi.org/10.1785/0120130125.

Ikari, M. J., Carpenter, B. M., \& Marone, C. (2016). A microphysical interpretation of rate-and state-dependent friction for fault gouge. Geochemistry Geophysics Geosystems, 17(5), $1660-1677$.

Ikari, M. J., Marone, C., \& Saffer, D. M. (2011). On the relation between fault strength and frictional stability. Geology, 39(1), $83-86$.

Johnson, K. M., Hsu, Y. J., Segall, P., \& Yu, S. B. (2001). Fault geometry and slip distribution of the 1999 Chi-Chi, Taiwan earthquake imaged from inversion of GPS data. Geophysical Research Letters, 28(11), 2285-2288.

Kaneko, Y., Avouac, J. P., \& Lapusta, N. (2010). Towards inferring earthquake patterns from geodetic observations of interseismic coupling. Nature Geoscience, 3(5), 363-369.

Kato, N. (2003). Repeating slip events at a circular asperity: Numerical simulation with a rate-and state-dependent friction law. Bulletin of the Earthquake Research Institute University of Tokyo, 78, 151-166.

Kato, N. (2014). Deterministic chaos in a simulated sequence of slip events on a single isolated asperity. Geophysical Journal International, 198(2), 727-736.

Lambert, V., \& Barbot, S. (2016). Contribution of viscoelastic flow in earthquake cycles within the lithosphere-asthenosphere system. Geophysical Research Letters, 43, 19.

Lapusta, N., \& Barbot, S. (2012). Models of earthquakes and aseismic slip based on laboratory-derived rate-and-state friction laws. The Mechanics of Faulting From Laboratory to Real Earthquakes, 2012, 153-207.

Lapusta, N., \& Rice, J. R. (2003). Nucleation and early seismic propagation of small and large events in a crustal earthquake model. Journal of Geophysical Research Solid Earth, 108, B4.

Lapusta, N., Rice, J. R., Ben-Zion, Y., \& Zheng, G. (2000). Elastodynamic analysis for slow tectonic loading with spontaneous rupture episodes on faults with rate-and state-dependent friction. Journal of Geophysical Research Solid Earth, 105(B10), 23765-23789.

Lavé, J., \& Burbank, D. (2004). Denudation processes and rates in the Transverse Ranges, southern California: Erosional response of a transitional landscape to external and anthropogenic forcing. Journal of Geophysical Research Earth Surface, 109, F1.

Lavé, J., Yule, D., Sapkota, S., Basant, K., Madden, C., Attal, M., et al. (2005). Evidence for a great Medieval earthquake ( 1100 $\mathrm{AD})$ in the central Himalayas, Nepal. Science, 307(5713), 1302-1305.

Lee, S. J., \& Ma, K. F. (2000). Rupture process of the 1999 ChiChi, Taiwan, earthquake from the inversion of teleseismic data. Terrestrial Atmospheric and Oceanic Sciences, 11(3), 591-608.

Li, D., \& Liu, Y. (2016). Spatiotemporal evolution of slow slip events in a nonplanar fault model for northern Cascadia subduction zone. Journal of Geophysical Research Solid Earth, 121(9), 6828-6845.

Liu, Y., \& Rice, J. R. (2005). Aseismic slip transients emerge spontaneously in three-dimensional rate and state modeling of subduction earthquake sequences. Journal of Geophysical Research Solid Earth, 110, B8.

Liu, Y., \& Rice, J. R. (2007). Spontaneous and triggered aseismic deformation transients in a subduction fault model. Journal of Geophysical Research Solid Earth, 112, B9.
Liu, Y., \& Rice, J. R. (2009). Slow slip predictions based on granite and gabbro friction data compared to GPS measurements in northern Cascadia. Journal of Geophysical Research Solid Earth, 114, B9.

Marone, C. J., Scholtz, C. H., \& Bilham, R. (1991). On the mechanics of earthquake afterslip. Journal of Geophysical Research Solid Earth, 96(B5), 8441-8452.

Marshall, S. T., Funning, G. J., \& Owen, S. E. (2013). Fault slip rates and interseismic deformation in the western Transverse Ranges, California. Journal of Geophysical Research Solid Earth, 118(8), 4511-4534.

McAuliffe, L. J., Dolan, J. F., Rhodes, E. J., Hubbard, J., Shaw, J. H., \& Pratt, T. L. (2015). Paleoseismologic evidence for largemagnitude $\left(M_{w}\right.$ 7.5-8.0) earthquakes on the Ventura blind thrust fault: Implications for multifault ruptures in the Transverse Ranges of southern California. Geosphere, 11(5), 1629-1650. https://doi.org/10.1130/ges01123.1.

McPhillips, D., \& Scharer, K. M. (2018). Quantifying uncertainty in cumulative surface slip along the Cucamonga Fault, a crustal thrust fault in southern California. Journal of Geophysical Research Solid Earth, 123(10), 9063-9083.

Mele Veedu, D., \& Barbot, S. (2016, April). The Parkfield Tremors: Slow and fast ruptures on the same asperity. In EGU General Assembly Conference Abstracts (vol. 18, p. 16555).

Michel, S., Avouac, J. P., Lapusta, N., \& Jiang, J. (2017). Pulselike partial ruptures and high-frequency radiation at creepinglocked transition during megathrust earthquakes. Geophysical Research Letters, 44(16), 8345-8351.

Noda, H., \& Hori, T. (2014). Under what circumstances does a seismogenic patch produce aseismic transients in the later interseismic period? Geophysical Research Letters, 41(21), 7477-7484.

Noda, H., \& Lapusta, N. (2013). Stable creeping fault segments can become destructive as a result of dynamic weakening. Nature, 493(7433), 518-521.

Qiu, Q., Hill, E. M., Barbot, S., Hubbard, J., Feng, W., Lindsey, E. O., et al. (2016). The mechanism of partial rupture of a locked megathrust: The role of fault morphology. Geology, 44(10), 875-878.

Rockwell, T. K., Clark, K., Gamble, L., Oskin, M. E., Haaker, E. C., \& Kennedy, G. L. (2016). Large Transverse Range earthquakes cause coastal upheaval near Ventura, southern California. Bulletin of the Seismological Society of America, 106(6), 2706-2720.

Rockwell, T. K., Keller, E. A., Clark, M. N., \& Johnson, D. L. (1984). Chronology and rates of faulting of Ventura River terraces, California. Geological Society of America Bulletin, 95(12), 1466-1474.

Rollins, C., Avouac, J. P., Landry, W., Argus, D. F., \& Barbot, S. (2018). Interseismic strain accumulation on faults beneath Los Angeles, California. Journal of Geophysical Research Solid Earth, 123(8), 7126-7150.

Romanet, P., Bhat, H. S., Jolivet, R., \& Madariaga, R. (2018). Fast and slow slip events emerge due to fault geometrical complexity. Geophysical Research Letters, 45(10), 4809-4819.

Rousset, B., Barbot, S., Avouac, J. P., \& Hsu, Y. J. (2012). Postseismic deformation following the 1999 Chi-Chi earthquake, Taiwan: Implication for lower-crust rheology. Journal of Geophysical Research Solid Earth, 117, B12.

Rubin, C. M., Lindvall, S. C., \& Rockwell, T. K. (1998). Evidence for large earthquakes in metropolitan Los Angeles. Science, 281(5375), 398-402. 
Ruina, A. (1983). Slip instability and state variable friction laws. Journal of Geophysical Research Solid Earth, 88(B12), 10359-10370.

Ryan, K. J., Geist, E. L., Barall, M., \& Oglesby, D. D. (2015). Dynamic models of an earthquake and tsunami offshore Ventura, California. Geophysical Research Letters, 42(16), 6599-6606.

Sapkota, S. N., Bollinger, L., Klinger, Y., Tapponnier, P., Gaudemer, Y., \& Tiwari, D. (2013). Primary surface ruptures of the great Himalayan earthquakes in 1934 and 1255. Nature Geoscience, 6(1), 71-76.

Sarna-Wojcicki, A. M., Williams, K. M., \& Yerkes, R. F. (1976). Geology of the Ventura Fault, Ventura County, California (No. 781).

Sarna-Wojcicki, A. M., \& Yerkes, R. F. (1982). Comment on Article by RS Yeats on "Low-Shake Faults of the Ventura Basin, California".

Scholz, C. H. (1998). Earthquakes and friction laws. Nature, 391, $37-42$.

Segall, P. (2012). Understanding earthquakes. Science, 336(6082), 676-677.

Shaw, J. H., \& Shearer, P. M. (1999). An elusive blind-thrust fault beneath metropolitan Los Angeles. Science, 283(5407), 1516-1518.

Shibazaki, B., Matsuzawa, T., Tsutsumi, A., Ujiie, K., Hasegawa, A., \& Ito, Y. (2011). 3D modeling of the cycle of a great TohokuOki earthquake, considering frictional behavior at low to high slip velocities. Geophysical Research Letters, 38, 21.

Sreejith, K. M., Sunil, P. S., Agrawal, R., Saji, A. P., Ramesh, D. S., \& Rajawat, A. S. (2016). Coseismic and early postseismic deformation due to the 25 April 2015, $\mathrm{M}_{\mathrm{w}} 7.8$ Gorkha, Nepal, earthquake from InSAR and GPS measurements. Geophysical Research Letters, 43(7), 3160-3168.

Suppe, J. (2007). Absolute fault and crustal strength from wedge tapers. Geology, 35(12), 1127-1130.
Thomas, M. Y., Avouac, J. P., \& Lapusta, N. (2017). Rate-andstate friction properties of the Longitudinal Valley Fault from kinematic and dynamic modeling of seismic and aseismic slip. Journal of Geophysical Research Solid Earth, 122(4), 3115-3137.

Tse, S. T., \& Rice, J. R. (1986). Crustal earthquake instability in relation to the depth variation of frictional slip properties. Journal of Geophysical Research Solid Earth, 91(B9), 9452-9472.

Wang, K., \& Fialko, Y. (2015). Slip model of the $2015 \mathrm{M}_{\mathrm{w}} 7.8$ Gorkha (Nepal) earthquake from inversions of ALOS-2 and GPS data. Geophysical Research Letters, 42(18), 7452-7458.

Wesnousky, S. G. (2006). Predicting the endpoints of earthquake ruptures. Nature, 444(7117), 358.

Wu, Y., \& Chen, X. (2014). The scale-dependent slip pattern for a uniform fault model obeying the rate-and state-dependent friction law. Journal of Geophysical Research Solid Earth, 119(6), 4890-4906.

Yu, S. B., Kuo, L. C., Hsu, Y. J., Su, H. H., Liu, C. C., Hou, C. S., et al. (2001). Preseismic deformation and coseismic displacements associated with the 1999 Chi-Chi, Taiwan, earthquake. Bulletin of the Seismological Society of America, 91(5), 995-1012.

Yu, H., Liu, Y., Yang, H., \& Ning, J. (2018). Modeling earthquake sequences along the Manila subduction zone: Effects of threedimensional fault geometry. Tectonophysics, 733, 73-84.

Yue, L. F., Suppe, J., \& Hung, J. H. (2005). Structural geology of a classic thrust belt earthquake: The 1999 Chi-Chi earthquake Taiwan $\left(\mathrm{M}_{\mathrm{w}}=7.6\right)$. Journal of Structural Geology, 27(11), 2058-2083.

Zhao, W. L., Davis, D. M., Dahlen, F. A., \& Suppe, J. (1986). Origin of convex accretionary wedges: Evidence from Barbados. Journal of Geophysical Research Solid Earth, 91(B10), $10246-10258$. 